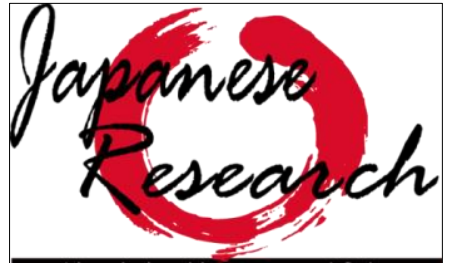

on Linguistics, Literature and Culture
Japanese Research on Linguistics, Literature, and Culture Vol. 2 No. 1 Nov. 2019, p., 36-45 ISSN Online: 2655-4836

DOI: $10.33633 /$ jr.vlil.3132

http://publikasi.dinus.ac.id/index.php/jrllc/article/view/3132/1875 japanese.research@fib.dinus.ac.id

Published by Universitas Dian Nuswantoro, Semarang

\title{
Humor dalam Anime Gekkan Shoujo Nozaki-Kun
}

\author{
Devia Rizka Athaariqa \\ CFLT Semarang \\ devia.rizka@cflt.id
}

Article History: Submitted date 2019-10-28; Accepted date 2019-11-3; Published date 2019-11-20

\begin{abstract}
The purpose of this study was to describe humor based on the theory of incongruity in the "Gekkan Shoujo Nozaki-kun " anime and categorized based on Graeme Ritchie theory. The data of this study were Nozaki Umetarou's and Seo Yuzuki's utterances in the Gekkan Shoujo Nozaki-kun anime which assumed to contain incongruity in the character's utterances thus creating humorous effect. The data were then gathered and analyzed based on the theory of incongruity by Immanuel Kant and categorized based on Graeme Ritchie theory. The research method used in this study was descriptive qualitative and under the study of pragmatics. The results of this study are, humour can be happened because the speaker's speech does not match with the expectations by the speech partner, then causing the speech partner to be surprised. The shock was realized as something funny by the speech partner. The types of incongruity that occur were inappropriateness, contrast, and conflict.
\end{abstract}

Keyword: Humor, Incongruity, Ritchie

\begin{abstract}
Abstrak
Penelitian ini bertujuan untuk mendeskripsikan humor berdasarkan teori incongruity pada anime "Gekkan Shoujo Nozaki-kun" dan dikategorikan berdasarkan teori Graeme Ritchie. Data penelitian ini berupa tuturan-tuturan Nozaki Umetarou dan Seo Yuzuki dalam anime Gekkan Shoujo Nozaki-kun yang diasumsikan mengandung incongruity atau kejanggalan pada tuturan tokoh tersebut sehingga memberikan efek humor pada penonton. Penelitian ini bersifat deskriptif kualitatif dengan ancangan pragmatik. Hasil penelitian yaitu humor dapat terjadi karena tuturan penutur tidak sesuai ekspektasi yang diharapkan mitra tutur sehingga menyebabkan mitra tutur terkejut. Keterkejutan tersebut kemudian disadari sebagai sesuatu yang lucu oleh mitra tutur. Adapun jenis incongruity yang terjadi adalah inappropriateness, conflict, dan contrast.
\end{abstract}

Kata kunci: Humor, Incongruity, Ritchie 


\section{Pendahuluan}

Kelucuan atau humor berlaku bagi manusia normal, untuk menghibur karena "hiburan" merupakan kebutuhan mutlak bagi manusia untuk ketahanan diri dalam proses pertahanan hidupnya (Widjaja,1993). Kelucuan juga selalu kena-mengena dengan hal-hal yang tidak wajar atau umum. Yang wajar dan umum, tidak memerlukan "perbaikan" atau tidak lagi menyediakan "wadah" untuk menjadi lucu. Hal-hal yang aneh dan "nyleneh" dapat menjadikan humor (Setiawan, 1990). Tidak menutup kemungkinan bahwa segala sesuatu yang ada didunia dapat dijadikan bahan untuk bercanda atau lelucon. Plato, Cicero, Aristoteles, dan Fransis Bacon (dalam Gauther, 1988) mengatakan bahwa orang akan tertawa apabila ada sesuatu yang menggelikan dan di luar kebiasaan. Menggelikan dapat diartikan sesuatu yang tidak sesuai dengan aturan atau sesuatu yang sangat jelek.

Teori humor tergolong dalam tiga macam, yaitu Superiority theory, Incongruity theory, dan Relief theory . Superiority theory atau teori superioritas menjelaskan bahwa setiap humor yang terjadi jika seseorang yang dianggap superioritas atau berkuasa dapat menciptakan humor dengan memanfaatkan kekeliruan yang dilakukan orang lain. Relief theory atau teori pembebasan merupakan suatu pelepasan yang dilakukan seseorang untuk mendapatkan rasa humor. Incongruity menjelaskan terjadinya humor akibat ketidak sesuaian atau keganjilan yang melanggar pola dan harapan mitra tutur. Cicero, Bab 63, Buku II, On the Orator " mengatakan jenis lelucon yang paling lucu adalah apa yang kita harapkan tidak sesuai dengan apa yang dikatakan, kekecewan tersebut yang membuat kita tertawa" (Morreall 1987a, 18). Yus (1997) (dalam Francisco Yus, 2017) mengemukakan bahwa teori incongruity resolution mengklaim bahwa kebanyakan lelucon memiliki pola yang sama, pendengar akan memproses lelucon yang disampaikan oleh penutur, dan secara tiba-tiba akan terjadi keganjilan atau ketidaksesuaian sehingga pendengar harus mencari solusi untuk mendapatkan efek humor yang diinginkan. Suls $(1972,1977,1983)$ dalam penelitian yang mengungkapkan sebagian besar teks humor memiliki pola, jika seseorang menemukan kejanggalan atau ketidaksesuaian dalam punchline atau kartun dan kemudian orang tersebut akan mencoba untuk memahami kejanggalan atau ketidaksesuaian tersebut dengan membentuk sebuah lelucon atau kartun dari pemikiran sendiri. 
Salah satu anime yang mengangkat genre humor adalah Gekkan Shoujo Nozaki-kun yang diciptakan oleh Izumi Tsubaki sebagai mangaka yang dirilis pada 7 Juli 2014 hingga 22 September 2014. Anime tersebut memiliki tujuh karakter utama yaitu Nozaki Umetarou, Sakura Chiyo, Mikoshiba Mikoto, Seo Yuzuki, Kashima Yuu, Hori Masayuki dan Wakamatsu Hirotaka. Gekkan Shoujo Nozaki-kun adalah anime yang mengisahkan kehidupan percintaan remaja disertai dengan humor. Sakura Chiyo merupakan murid SMA yang jatuh cinta kepada seorang murid yang bernama Nozaki Umetarou. Sakura mencoba menyatakan perasaannya kepada Nozaki, namun Nozaki salah paham dan menjadikan Sakura sebagai asisten.

Kelucuan pada anime ini terdapat pada tuturan tokoh Gekkan Shoujo Nozaki-kun ketika berkomunikasi. Hal ini dijadikan dasar oleh penulis untuk meneliti tuturan tokoh yang dianggap ganjil.

\subsection{Metode Penelitian}

Penelitian ini disusun dengan paradigma kualitatif berancangan pragmatik dengan metode analisis deskriptif tentang kejanggalan atau ketidaksesuaian tuturan tokoh anime Gekkan Shoujo Nozaki-kun sehingga terjadi humor. Penulis berusaha mendeskripsikan konteks percakapan dalam tuturan humor, dan mendeskripsikan kejanggalan atau ketidaksesuaian tuturan sehingga terjadi humor.

Penelitian ini berfokus pada tuturan tokoh anime Gekkan Shoujo Nozaki-kun. Penulis mendeskripsikan konteks pada saat tuturan berlangsung serta mendeskripsikan tuturan yang mengandung kejanggalan atau ketidaksesuaian yang menyebabkan humor.

Langkah-langkah yang dilakukan penulis dalam mengumpulkan data yaitu : 1) Penulis menggunakan teknik simak terhadap sumber data untuk menemukan tuturan-tuturan tokoh anime Gekkan Shoujo Nozaki-kun yang mengandung humor, 2) Mengidentifikasi humor dengan menggunakan teori incongruity, 3) Validasi data kepada native speaker, 4) Kategorisasi data berdasarkan tuturan tokoh Nozaki Umetarou dan Seo Yuzuki yang mengandung humor.

Kemudian penulis akan melakukan analisis data dengan cara berikut: 1) Menganalisis

konteks percakapan yang mengandung humor dalam tuturan tokoh anime Gekkan Shoujo Nozaki-kun, 2) Mengidentifikasi punchline yang menjadi penyebab humor berdasarkan teori 
Incongruity, 3) Mendeskripsikan secara komprehensif terjadinya humor berdasarkan konteks dan teori incongruity, 4) Kategorisasi data berdasarkan teori Graeme Ritchie..

\section{Hasil dan Pembahasan}

Dalam anime Gekkan Shoujo Nozaki-kun ditemukan 20 dialog tokoh Seo Yuzuki dan Nozaki Umetarou yang mengandung kejanggalan. Setelah tuturan dikumpulkan dan dianalisis, ditemukan 9 tuturan yang termasuk dalam kategori inappropriateness, 10 kategori conflict, dan 8 kategori contras.

1) Inappropriateness

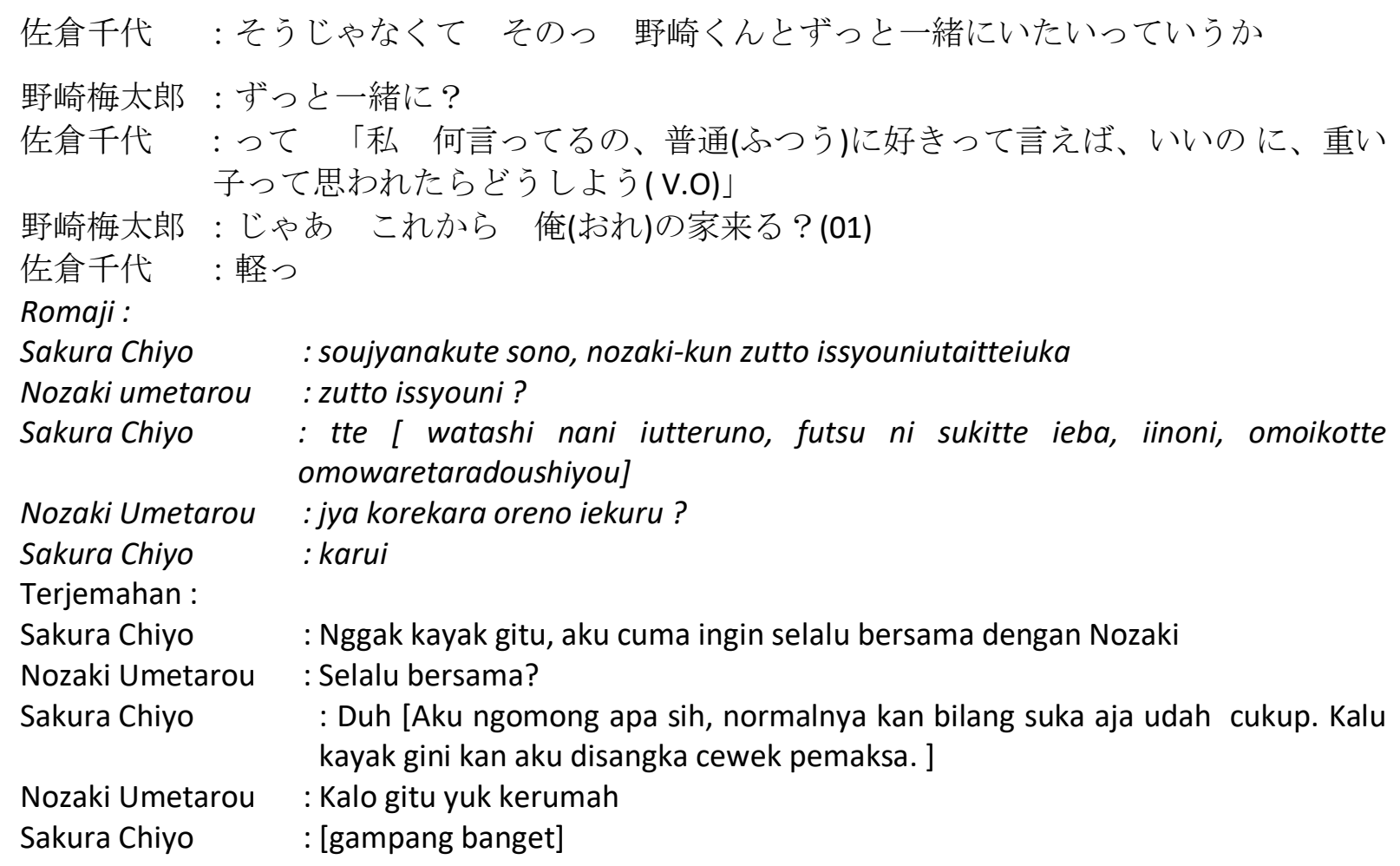

\section{Konteks dialog 1}

Partisipan dialog 1 terjadi antara Nozaki Umetarou dan Sakura Chiyo. Nozaki merupakan seorang pembuat komik atau mangaka, sedangkan Sakura hanya seorang murid biasa. Mereka berasal dari kelas yang berbeda. Ketika pulang sekolah mereka bertemu di sebuah ruang kelas. Sakura bermaksud untuk mengungkapkan perasaanya kepada Nozaki, tapi Sakura tidak mengungkapkan perasaannya dan berkata hal yang aneh. Sakura berkata bahwa ia ingin selalu bersama dengan Nozaki. Namun tidak seperti yang dipikirkan Sakura, bahwa Nozaki akan 
merasa tidak nyaman kalau Sakura selalu bersamanya. Tanpa pikir panjang Nozaki langsung mengajak Sakura ke rumahnya.

\section{Analisis Data 1}

Kelucuan dalam dialog di atas adalah じゃあ これから 俺(おれ)の家来る?yang berarti “ Kalau begitu ayo kerumahku “. Tuturan tersebut dianggap lucu karena di luar dugaan membuat mitra tutur terkejut. Tuturan sebelumnya menjelaskan harapan atau ekspektasi Sakura yaitu jika Sakura mengatakan ingin selalu bersama Nozaki, Nozaki akan membalas tuturannya dengan mengatakan bahwa Sakura adalah 'anak yang berat' atau omoiko. Kehidupan di Jepang, kata omoiko digunakan oleh seseorang yang memiliki pasangan tetapi selalu ingin bersama kapan saja dan memiliki makna yang cenderung negatif. Sakura tidak ingin Nozaki merasa tidak nyaman dengan Sakura

Tidak seperti dugaan Sakura, Nozaki justru mengajak Sakura ke rumahnya. Di Jepang, tidak lazim mengajak orang yang belum akrab ke rumah. Namun tuturan Nozaki bertentangan dengan kebudayaan Jepang, sehingga membuat tuturan Nozaki menjadi lucu karena membuat Sakura dan penonton terkejut. Kelucuan juga ditegaskan oleh tuturan Sakura yaitu 軽つ atau karutsu yang berarti gampang banget. Tuturan Nozaki membuat Sakura terkejut, sehingga dalam hati Sakura mengatakan bahwa gampang banget Nozaki mengajaknya ke rumah.

Tuturan Nozaki じやあ これから＼cjkstart俺(おれ)の家来る? tidak sesuai dengan budaya Jepang. Mengajak seseorang yang baru dikenal kerumah merupakan perbuatan yang dianggap tidak wajar oleh masyarakat Jepang, karena sifat orang Jepang selalu tertutup terhadap orang yang baru dikenal.

\section{Hasil analisis data 1:}

Tuturan (01) menjadi punch lines dalam dialog 1. Sesuai dengan teori incongruity, tuturan ini menyebabkan situasi yang mengejutkan sehingga memicu kelucuan bagi pemirsa. Seandainya penutur mengatakan Sakura adalah omoiko yaitu ingin selalu dekat dengan Nozaki. Maka tidak terjadi situasi inkongruen yang menyebabkan humor.

\section{2) Conflict}

野崎梅太郎：いやー 助(たす)かった 今 誰も捕まらなくてさ 佐倉千代 : 「いつもは女の子連れ込み放題なの 


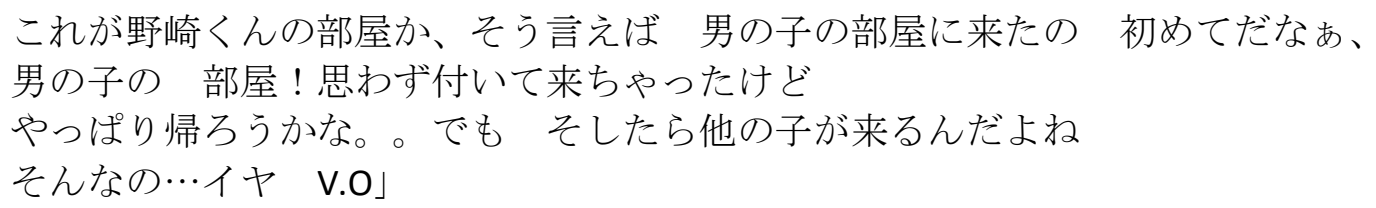

\section{Konteks dialog 2}

Partisipan dialog 2 terjadi antara Nozaki Umetarou dan Sakura Chiyo. Akhirnya Sakura ikut ke rumah Nozaki setelah Nozaki menawarkannya untuk berkunjung. Setelah sampai di rumah Nozaki, Nozaki mengatakan bahwa ia merasa sangat tertolong karena Sakura mau datang. Kemudian Sakura berfikir kalau ini merupakan pertama kalinya ia masuk ke kamar lakilaki. Sakura sempat berfikir bahwa ia ingin pulang saja, namun Sakura khawatir kalau ada perempuan lain yang datang ke rumah Nozaki. Kemudian Nozaki keluar dari dapur dan menyajikan minuman untuk Sakura dan Sakura berkata bahwa ia akan bersungguh-sungguh. Maksud Sakura adalah bersungguh-sungguh untuk mendekati Nozaki sehingga tidak ada 
perempuan lain yang datang. Nozaki langsung memberikan kertas dan meminta tolong Sakura untuk menghitamkan beberapa bagian pada komiknya. Beta merupakan suatu kode yang digunakan oleh Nozaki untuk memudahkan seseorang yang membantunya mengerjakan manganya, bagian yang harus di hitamkan diberi kode Beta.

\section{Analisis dialog 2}

Kelucuan pada dialog di atas adalah “じやあ そこ ベタよろしく”, “黒く塗って ね”，“ここもよろしく“. Tuturan tersebut tidak sesuai dengan harapan mitra tutur. Sakura mengatakan “のっ 野崎くん＼cjkstart私 頑張(がんば)ります!” yang berarti Nozaki aku akan bersungguh-sungguh. Bersungguh-sungguh menurut konteks adalah Sakura ingin berusaha untuk menjalin hubungan dengan Nozaki, tetapi Nozaki tidak mengetahui bahwa sebenarnya Sakura menyukai Nozaki. Jawaban Nozaki yang diharapkan adalah Nozaki akan memberi semangat kepada Sakura untuk menjalin hubungan yang lebih dari teman.

Namun harapan tersebut dijatuhkan dengan tuturan “じやあ そこ ベタよろしく” yang berarti kalau begitu, kerjakan BETA di sini ya dan dipertegas dengan tuturan “黒く塗つ てね” yang berarti tolong hitamkan ya, dan “ここもよろしく “yang berarti yang di sini juga. Tuturan tersebut memiliki kelucuan karena menjatuhkan harapan mitra tutur sehingga mitra tutur kecewa. Harapan Sakura dan penonton adalah mendapatkan semangat dari Nozaki malah berubah dan Nozaki menyuruh Sakura untuk membantunya menghitamkan bagian pada manga karyanya.

Punchline terdapat kelucuan karena terdapat pembelokan fokus. Tuturan Nozaki tidak berfokus pada set up tetapi lebih fokus terhadap pekerjaan Nozaki.

\section{Hasil analisis data 2:}

Tuturan (01) dan menjadi punch lines dalam dialog 2. Sesuai dengan teori incongruity, tuturan ini menyebabkan situasi yang mengejutkan sehingga memicu kelucuan bagi pemirsa. Seandainya penutur mengatakan aku juga akan berjuang untuk hubungan kita. Maka tidak terjadi situasi inkongruen yang menyebabkan humor. 


\section{3) Contras}

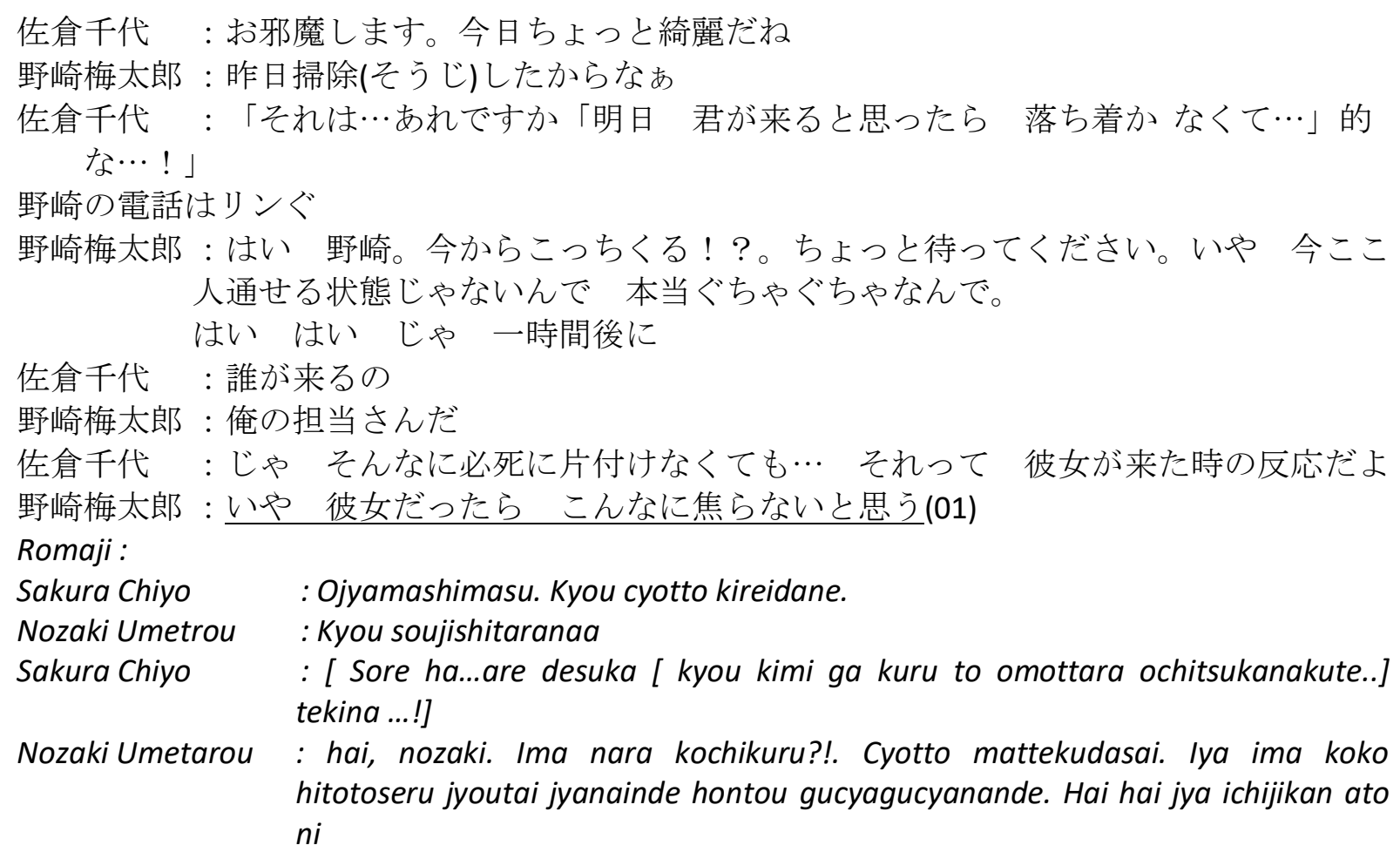

Sakura Chiyo: daregakuruno

Nozaki Umetarou :Oreno tantousanda

Sakura Chiyo : jya sonnani hisshini katadzukenakutemo... sorette kanojyo ga kita toki no hannoudayo

Nozaki Umetarou : iya kanojyodattara konnani aseranaito omou

Terjemahan :

Sakura Chiyo : Maaf menggangu. Hari ini lumayan bersih ya

Nozaki Umetarou : Kemarin aku bersih-bersih

Sakura Chiyo : : [ Apakah ini [karena besok kamu akan datang, aku jadi merasa bersalah ] yang itu]

Telepon Nozaki berdering

Nozaki Umetarou : lya dengan Nozaki. Apa mau datang sekarang?! Tolong tunggu sebentar. Tempatku belum siap untuk menerima tamu saat ini karena sangat berantakan. lya baik, sampai bertemu satu jam lagi.

Sakura Chiyo: Siapa yang akan datang?

Nozaki Umetarou : Editorku

Sakura Chiyo : : Nggak perlu buru-buru merapikannya juga kan, reaksimu seperti pacarmu mau datang aja

Nozaki Umetarou : oh nggak, kalo itu pacarku, aku rasa aku nggak akan buru-buru kayak gini

\section{Konteks dialog 3}

Partisipan dialog terjadi antara Nozaki Umetarou dan Sakura Chiyo. Sakura berkunjung ke rumah Nozaki untuk membantu mengerjakan manga. Rumah Nozaki terlihat lebih bersih dari sebelumnya, Sakura mengira bahwa Nozaki membersihkan rumahnya karena mengetahui 
Sakura akan datang. Tiba-tiba telpon Nozaki berbunyi. Nozaki terlihat kebingungan dan mengatakan rumahnya belum siap untuk menerima tamu karena berantakan. Nozaki buru-buru membersihkan rumahnya. Setelah selesai menelpon, Sakura menanyakan siapakah yang akan datang. Nozaki berkata bahwa editornya. Sakura menyarankan tidak perlu terburu-buru karena hanya akan bertemu editor dan rekasi Nozaki seperti akan kedatangan pacar. Tapi jawaban Nozaki menjawab dia tidak akan terburu-buru membersihkan rumahnya jika pacarnya datang.

\section{Analisis dialog 3}

Tuturan いや 彼女だったら こんなに焦らないと思うyang oh nggak, kalo itu pacarku, aku rasa aku nggak akan buru-buru kayak gini. Harapan Sakura, Nozaki akan mengatakan kalau Nozaki membersihkan kamarnya karena tahu Sakura akan datang berkunjung. Karena Sakura ingin memiliki hubungan yang lebih dengan Nozaki, Sakura mengatakan reaksi Nozaki seperti pacarnya akan datang. Tuturan Nozaki いや 彼女だったら こんなに焦らないと思う memiliki kelucuan karena tidak sesuai dengan harapan mitra tutur dan membuat mitra tutur kecewa. Tuturan sebelumnya Nozaki mengatakan yang akan datang adalah editornya. Menurut Nozaki editor lebih penting daripada pacar.

Punchline memiliki kelucuan karena bertentangan dengan setup. Setup menjelaskan tindakan Nozaki seperti akan kedatangan pacarnya, tetapi tuturan Nozaki betentangan dengan setup sehingga memicu terjadinya humor.

\section{Hasil analisis data 3:}

Tuturan (01) menjadi punch lines dalam dialog 3. Sesuai dengan teori incongruity, tuturan ini menyebabkan situasi yang mengejutkan sehingga memicu kelucuan bagi pemirsa. Seandainya penutur mengatakan mungkin aku akan lebih buru-buru lagi kalau pacarku datang. Maka tidak terjadi situasi inkongruen yang menyebabkan humor.

\section{Simpulan}

Dari hasil penelitian, penulis menarik kesimpulan bahwa humor dapat terjadi karena tuturan penutur tidak sesuai ekspektasi yang diharapkan mitra tutur sehingga menyebabkan mitra tutur terkejut. Keterkejutan tersebut kemudian disadari sebagai sesuatu yang lucu oleh 
mitra tutur. Adapun jenis incongruity yang terjadi adalah inappropriateness, contrast, dan conflict.

\section{Referensi}

Brône, G., \& Feyaerts, K. (2003). The cognitive linguistics of incongruity resolution: Marked reference-point structures in humor. Preprints Katholieke Universiteit Leuven,Departement Linguistiek, 205(1964), 58. https://doi.org/10.4278/ajhp.121023QUAN-511

Lisa Amelia Anggelina Hartono. (2012). Teknik Humor dalam Film Warkop DKI.

Rahmanadji, D. (2007). Sejarah, Teori, Jenis, dan Fungsi Humor. Bahasa Dan Seni, 35(2), 213221.

Retrieved

from https://s3.amazonaws.com/academia.edu.documents/41878158/Sejarah-Teori-Jenisdan-Fungsi-Humor.pdf?AWSAccessKeyId=AKIAIWOWYYGZ2Y53UL3A\&Expires= 1515277850\&Signature=P\%2BPbotBFzZvN03fFM\%2Fq3y1I\%2FbOM\%3D\&responsecontent-disposition=inline\%3B filename\%3DSejar

Ritchie, G. (2010). Variants of Incongruity Resolution. Journal of Literary Theory, 3(2), 1-20. https://doi.org/10.1515/jlt.2009.015

Ritchie, G. (2011). Incongruity Resolution Incongruity Resolution and Humour and Humour. 1-5.

Saifudin, A. (2017). Penggunaan Manga Humor dalam Penelitian dan Pembelajaran Bahasa Jepang. Japanedu: Jurnal Pendidikan dan Pengajaran bahasa Jepang 2 (2), 99-113.

Saifudin, A., Risagarniwa, Y.Y., Citraresmana, E. (2017). Developing a Semiotics Analysis Tool of Humor in Manga: A Pilot Study of Cognitive and Cultural Representation in Humorous Comic. 6 th Global Conference on Business and Social Sciences on "Contemporary Issues in Business and Social Sciences Research" (CIBSSR - 2017). Bangkok: GATR..

Saifudin, A. (2018). Konteks dalam Studi Linguistik Pragmatik. LITE: Jurnal Bahasa, Sastra, dan Budaya, 14(2), 108-117.

Saifudin, A., Risagarniwa, Y. Y., Citraresmana, E., \& Sidiq, I. I. (2019). Pengembangan Alat Analisis Humor dalam Komik Jepang. Japanese Research on Linguistics, Literature, and Culture, 1(2), 129-143. https://doi.org/10.33633/jr.v1i2.2502

Straus, I. J. (2014). Incongruity Theory and the Explanatory Limits of Reason.

Tomáš Kulka. (2007). The Incongruity of Incongruity Theories of Humor. Tom áš Kulka. 14(3), 320-333.

Yus, F. (2017). Incongruity-resolution cases in jokes. Lingua, 197, 103-122. https://doi.org/10.1016/j.lingua.2017.02.002 